\title{
KONSEP RUMAH TANGGA BERPHBS PEMUKIMAN ROMBONG GANTA PADA SUKU ANAK DALAM DI KABUPATEN MERANGIN
}

\author{
The concepts of Househole in clean and healthy habit (PHBS) of ganta's indigenous \\ Community on Merangin District
}

\author{
M. Ridwan', Oka lesmana ${ }^{1}$ \\ ${ }^{1}$ Program Studi Ilmu Kesehatan Masyarakat Universitas Jambi
}

\begin{abstract}
Abstrak
Budaya melangun warga SAD Jambi pada kesehariannya menjadikan mereka sulit mendapatkan hak-hak sebagai warga Negara. Pemerintah sudah memberikan rumah tetapi akhirnya di tinggal atau di jual. Tujuan penelitian untuk mengembangkan konsep Perilaku hidup bersih dan sehat yang di butuhkan dan dapat diterapkan ketika menghuni rumah sehingga perpindahan dari pemikiman sudung ke pemukiman menetap memiliki ketrampilan dalam menjaga kebersihan. Penelitian kualitatif dengan design studi kasus. Metode pengambilan sampel secara purposive sampling, pengambilan data dengan wawancara mendalam, dan FGD. Analisis Data menggunakan pendekatan content analysis. Warga SAD pada awalnya dari pemukian berpindah (Sudung) ketika menghuni rumah tidak serta merta mampu menyesuaikan sebagaimana fungsi rumah yang sebenarnya. kondisi lingkungan pemukian tidak terawat, perilaku hidup bersih misalnya mencuci tangan pakai sabun. mencuci pakaian. Mandi, memotong kuku. dan memaksakan makanan ternyata belum sepenuhnya masyarakat SAD paham dan mampu melakukan. Dari hasil penelitian ini ketika di berikan rumah maka warga SAD harus di bekali dengan pemahaman tentang kebersihan diri ,dan lingkungan. Penyelesaian Masalah Kesehatan Masyarakat SAD Konsep PHBS bagi warga SAD dapat dilakukan untuk mempercapat perubahan perilaku. Pola pendampingan dengan 'Live in' atau tinggal bersama mereka lebih lama dan memberikan contoh sebanyak-banyak akan mempercepat perubahan perilaku warga Suku anak Dalam (SAD)
\end{abstract}

Kata Kunci : Pemberdayaan, SAD, PHBS SAD

\begin{abstract}
The culture of developing SAD Jambi residents on a daily basis makes it difficult for them to obtain rights as citizens. The government has provided the house to eventually live or sell. The aim of the research to develop the concept of clean and healthy life that is needed and can be applied to occupy the house must be applied from the settlement of the sudung to the settlement having skills in hygiene needs. Qalitative research with case studies. The method of sampling was purposive sampling, data collection by in-depth interviews, and FGD. Data analysis using content analysis. SAD residents initially compiled from the shifting (Sudung) inhabiting the house did not necessarily be able to adjust to allow the actual house. Conditions of Bathing Environment Unkempt, Clean Life Behavior washing clothes. Take a shower, cut the nails. and forcing food does not bind the SAD community to understand and be able to do it. From the results of this study the compilation at home provided by SAD residents must be equipped with an understanding of personal hygiene, and the environment. Overcoming SAD's Public Health Problems The concept of PHBS for SAD residents can be done to accelerate policy changes. The pattern of assisting with 'Staying in' or staying with them longer and giving more examples will improve the changes in the Suku Anak Dalam (SAD) community
\end{abstract}

Key Word: Empowerment, SAD, PHBS SAD

Korespondensi: M.Ridwan

Email: ridwannaura@yahoo.co.id

\section{PENDAHULUAN}

Suku anak dalam sebagai Komunitas minoritas yang yang ada di provinsi Jambi harus terus dilakukan pembenahan-pembenahan untuk mencapai kejahterannya. Suku Anak Dalam dalam Provinsi Jambi mendiami delapan wilayah di kabupaten dan Kota yaitu Kabupaten Muaro Jambi, Batanghari,
Tebo, Sarolangun, Merangin, Bungo, Tanjab Barat, dan Tanjab Timur. Dari hasil Pendataan yang dilakukan di dapatkan bahwa jumlah Komunitas Adat Terpencil (KAT) di Provinsi Jambi tahun 2011 sebanyak $6.773 \mathrm{KK}$ atau 28.886 jiwa. sebanyak $3.489 \mathrm{KK}$ atau 14.947 jiwa belum pernah memperoleh pembinaan dan yang pernah 
memperoleh pembinaan masih belum juga menunjukan hasil sesuai yang diharapkan (Dinsosdukcapil, 2011). Sedangkan ditahun 2014, jumlah Komunitas Adat Terpencil Suku Anak Dalam dan Suku Duano di Provinsi Jambi sebanyak 3.147 KK yang tersebar di 8 Kabupaten, 18 Kecamatan, 20 Desa dan 28 lokasi. Muaro Jambi (75 KK), Batanghari (620 KK), Tebo (415 KK), Sarolangun (249 KK), Merangin (165 KK), Bungo (128 KK), Tanjab Barat (100 KK) dan Tanjab Timur $(76 \mathrm{KK}){ }^{1}$

Permasalahan PHBS pada orang rimba seperti masih tingginya orang rimba melahirkan dengan dukun, masih adanya bayi yang tidak ditimbang secara berkala dan tidak diberi ASI eksklusif, masih adanya orang rimba tidak menggunakan jamban ketika BAB \& BAK, tidak melakukan sikat gigi, tidak menggunakan air bersih, tidak membuang sampah pada tempatnya, tidak membersihkan perkarangan, merokok, masih adanya tidak memiliki KIS. ${ }^{2}$

Nilai-nilai yang dianut masyarakat Indonesia tidak sesuai dengan budaya Suku Anak Dalam. Salah satunya Suku Anak Dalam yang masih menganut budaya melangun yang menyebabkan terhambatnya aktifitas yang dilakukan Suku Anak Dalam, terhenti lalu mereka mencari tempat hunian lain dihutan ${ }^{3 .}$. Pada program pemberdayaan, masyarakat adat hanya terlibat dalam tahap pelaksanaan sehingga masyarakat terbiasa menunggu program yang dirumuskan oleh Pemerintah namun tidak dilibatkan ketika merumuskan apa yang menjadi kebutuhan dan harapan masyarakat adat tersebut ${ }^{4}$

Dari hasil observasi lapangan di desa sialang kecamatan pamenang suku anak dalam sudah di berkan hunian sebanyak 15 unit yang di gunakan pada rombong ganta. 10 unit rumah di huni oleh masyarakat setempat. Tujuan dari upaya ini adalah agar masyarakat SAD lebih cepat terintgrasikan dengan masyarakat setempat. Pada dasarnya pemerintah telah memberikan perhatian kepada masyarakat terasing ini dalam aspek pembangunan sosial. Pemerintah berusaha untuk meningkatkan dan memperbaiki kehidupan sosio-ekonomi masyarakat itu. Peran lembaga swadaya masyarakat semakin aktif tetapi untuk permasalahan perilaku sehat masih menjadi permasalahan tersendri. Rumah yang diberikan oleh pemerintah kepada Rombong ganta melalui dinas sosial pada saat ini sudah di tempati dengan baik oleh warga SAD rombong ganta. Kondisi rumah yang di tempati masih belum menunjukkan fungsi-fungsi rumah sebagaimana yang menjadi kebutuhan dalam keluarga. beberapa perilaku yang menjadi permasalahan adalahmasih kurangnya kesadaran menggosok gigi, mandi memakai sabun, menyapu halaman, memasak air dengan benar, menggosok baju. Membersihkan lantai dan lain yang berhubungan dengan personal hygiene. Ketika Rumah di berikan belum adanya pedoman bagi warga SAD untuk layaknya rumah yang harus di tempati. Untuk itu sebuah konsep perilaku hidup besih dan sehat perlu di persiapkan sesuai dengan kondisi warga SAD di harapkan setelah menempati rumah kemampuan berperialku hidup sehat dapat terwujud.

\section{METODE}

penelitian kualitatif dengan design studi kasus, berlokasi di desa Sialng Rombong ganta kabupaten Merangin Jambi. Metode pengambilan sampel secara purposive sampling, pengambilan data dengan wawancara mendalam, dan FGD. Analisis Data menggunakan pendekatan content analysis. Responden penelitian terdiri dari Tumenggung, warga suku anak dalam, NGO, Puskesmas. dan dinas Sosial. Pengambilan data dengan cara wawancara mendalam, FGD dan observasi serta telaah dokumen.

\section{HASIL DAN PEMBAHASAN}

Dari hasil Observasi di lapangan Kondisi lingkungan pemukiman warga SAD di desa sialang masih menunjukkan kondisi yang belum baik. terlihat sampah-sampah berserakan di sekitar rumah. belum adanya tempat-tempat penampungan sampah maupun tempat pembuangan sampah sehingga di sekitar rumah kelihatn kotor dan tidak di bersihkan secara teratur. kondisi lingkungan di belakang rumah terlihat peralatan dapur berserakan dan tidak di susun dengan baik, peralatan bekas kegiatan masakmemasak Nampak tidak di cuci, lalat menguerbungi 
kuali, piring makan dan Baskom yang berserakan.dari hasil wawancara dengan responden berikut pernyataannya :

\section{... biasolah .. dak masalah jugo di samping} tempatnyo dak ado nak di tarok dimano(TG)

dari responden lainya dikaitkan bahwa:

..kita sudah memberitahu kepada mereka tetapi memang butuh waktu untuk berubah.. (pp)

Kondisi Rumah warga SAD terdiri dari 15 Rumah yang di huni oleh warga SAD dari 25 Rumah yang ada. 1 rumah tidak di tempai digunakan oleh pendamping atau tamu yang ingin menginap di pemukiman. Rumah Suku anak dalam kondisi kurang bersih baju-baju berserakan, bergelantungan di kamar tidur, di ruang tamu sedangkan yang di kamar tidur tidak tersusun dengan rapi. Penumpukan baju bersih dan kotor di campur sehingga menimbulkan bau yang kurang menyenangkan. bajubaju bergantungan di jendela. motor terlihat di masukkan kedalam kamar bercampur dengan pakaian. Kebiasaan sehari-hari warga SAD yang tidak mengepel lantai atau menyapu membuat lantai mendalam tidak membuka jendela di karenakan jendela terhalang dengan kain penutup jendela dan di paku. selain itu jendela sulit untuk di buka. dari hasil wawancara dengan beberapa warga SAD bahwa tidak membuka jendela di karenakan tidak mengetahui manfaat bila di buka jendela setiap hari. berikut kutipan wawancara :

Nampak kusam dan berdebu di seluruh ruangan. perilaku sehari - hari warga SAD tidak membuka jendela Rumah. dari hasil Observasi dan wawancara

... kadang kita malas buka jendela ...nanti ada yang masuk dari luar ......(WG.5)

pendapat lain dari warga SAD mengatakan bahwa : ... jendela sulit di buka .. keras susah menutup kembali..... (WG.4)

Dari hasil observasi lapangan dapat di lihat bahwa kondisi kebersihan diri warga sad masih sangat memperhatinkan. Dilihat dari kondisi kebersihan diri anak-anak terlihat Kebersihan kuku tampak terlihat, tidak di bersihkan secara teratur kuku hitam dan panjang. tentunya dapat menjadi perantara perpindahan penyakit. anak-anak ketika mau makan tidak mencuci tangan dengan sabun. mereka mencuci memakai air yang ada di tempattempat penampungan air tidak di bersihkan dengan baik hal ini dapat mengakibatkan tertularnya beberapa penyakit. rambut-rambut anak tidak tersisir dengan baik terlihat sangat kotor dan menombulkan bau yang kurang menyenangkan anak melaksnakan mandi tetapi tidak membersihkan dengan menggunkan sabun dan di gosok dengan baik sehingga kotoran-kotoran dapat hilang. kulit tubuh anak- anak terlihat bersisik dan hitam karena kotoran menempel di tubuh yang tidak di bersihkan.

Pakaian yang digunakan oleh warga SAD masih terlihat tidak rapi karena tidak melakukan penyetrikaan pada pakaian yang di gunakan. sehingga walaupun baju masih baru tetapi tidak menunjukkan kerapaian. Perilaku warga SAD yang laki- laki tidak memakai baju menjadi perhatian khusus terhadap kehidupan sosial. Hubungan komunikasi menjadi penghambat terhadap perilaku warga SAD yang tidak menggunakan baju.

Dari hasil wawancara mendalam dengan tenaga puskesmas, di katakan bahwa kegiatan puskesmas dengan warga SAD di desa Sialang pada saat ini belum dilakukan dengan terencana. kegiatankegiatan yang dilakukan oleh puskesmas adalah penyuluhan kepada warga SAD dengan mengundang ke puskesmas. Melakukan kunjungan ke warga di 4 desa wilayah kerja puskesmas tetapi hanya berupa kunjungan tetapi tidak dilakukan secara teratur dan terencana dengan baik. menjadi kesulitan dari pembinaan untuk warga SAD adalah karena warga SAD tidak bisa membaca dan bersosialisasi dengan baik. Hal ini di nyakatan oleh petugas puskesmas sebagai berikut :

...Kegiatan-kegiatan kami sudah banyak
dilakukan, misalnya mengundang SAD ke
puskesmas untuk
pembinaan tarsus kami lakukan.. (PKM)

Dari hasil wawancara mendalam dengan petugas pada tahun kedepan akan dianggarakan untuk SAD sehingga di harapkan dapat melakukan kegiatan secara rutin. dari hasil kegiatan dengan pendampingan yang dilakukan dengan berdirinya posyandu. Menjadi permasalahan adalah bahwa 
tenaga puskesmas selalu berganti-ganti penanggung jawab sehingga bila di ganti yang baru sulit maka membutuhkan waktu untuk mencari metode pendekatan kepada warga SAD. Ketika wawancara petugas yang di wawancrai mengatkan bahwa mereka baru mendapatkan tugas sehingga masih belum begitu mengerti pendekatan yang dilakukan terhadap warga SAD. metode apa yang harus dilakukan agar warga SAD dapat berperilaku hidup bersih dan sehat.

Pendamping Pundi sumatera dalam melakukan kegiatan-kegiatan selalu bermusyawarah dengan warga atau tumenggung ganta, sehingga apa saja yang dikerjakan maka warga terlebih dahulu di lakukan musyawarah dan menamakan persepsi. pendamping dari pundi sumatera setiap hari selalu hadir di tenagh -tengah rombong ganta di pemukiman untuk melakukan pendekatanpendekatan kepada warga. dari hasil tersebut maka warga SAD akan mau melakukan apa yang akan ingin di kerjakan. selain itu untuk meningkatkan kepercayaan tumenggung atau warga Rombong ganta. untuk pendampingan Pundi Sumatera juga terlebih dahulu melakuan assessment apakah Rombong itu mau di lakukan pendampingan atau tidak. terkadang banyak juga yang menolak untuk dilakukan pendampingan.

hal ini dapat di katakana oleh responden sebagai berikut :

..untuk pendampingan kita selalu di tempat dengan

"live in".. selain itu kita sebelum pendampingan juga bertanya apakah mau di damping atau tidak.. (PS.1)

Faktor -faktor yang mempermudah terjadinya perilaku warga SAD romong ganta adanya pendamping dari Ngo yang selalu mendampingi dan memberi pengetahuan tentang cara meningkatkan taraf hidup termasuk dalam pengetahuan di pendidikan kesehatan. kegiatan yang dilakukan adalah melatih pertukangan, melatih peternikan ikan Lele. dan kehidupan sehari-hari. dai hasil wawancara dengan NGO Pundi sumatera :

....kami melakukan kegiatan,, agar masyarakat SAD dapat bangkit dan mempunyai penghasilan...beberapa kegiatan misalnya melatih pertukangan, memelihara ikan dan kegiatan lainya. (PS.2)
Warga SAD Rombong ganta mayoritas agama Kristen. untuk itu mereka di damping oleh seorang yang berasal dari gereja. dalam kehidupan setiap bulannya mereka di berikan bahan-bahan pokok, misalnya beras, minyak sayur dan kebutuhan lainya. sudah lama bantuan ini di berikan kepada Rombong ganta. meraka sangat patuh dengan pendamping agama ini hal ini di karenaka sifat ketergantunga mereka sangat tinggi. apapun yang di katakana pendaping keagaam mereka akan patuhi. sehingga ketika kita mengaarkan perialku sehat maka kita berkoordinasi dengan pendamping agama. hal ini akan memudahkan kita dalam merubah persepsi dan pendapat. yang terpentng adalah adanya pendamping yang dapat memberikan contoh. pendamping keagamaan merupakn factor penentu dalam penggerakan masyarakat SAD Rombong ganta. rasa hormat dan kepatuhan mereka suatu pendorong untuk mempermudah dalamperubahan perilaku individu, hal in dinyatakan sebagai berikut :

Dari hasil wawancara mendalam dengan responden dikatakan bahwa mereka dapat dilakukan pembinaan karena kehidupannya masih sangat tergantung dari bantan-bantuan yang di berikan pendamping. pendamping Rombong ganta dari kegaamam memberikan minyak sayur beras, peralatan daputr lainya sehingga hal ini menjadi strategi dalam pendekatan dan penggerakan. Mereka sangat patuh kepada donor yang memberikan bantuan hidup bagi mereka. Hal ini yang mempermudah dalam perubahan perilaku sehat yang dilakukan. Masyarakat SAD Rombong ganta masih sangat ketergantungan terhaap bantuan. kehadiran bantuan merupakan seautu yang menjadi panutan bagi mereka. hasil Buruan yang tidak menentu membuat mereka sangat bergantung kepada pendamping yang memberikan bantuan.hal ini di sampikan oleh responden : ... mereka sangat patuh dengan saya. bila merka tidak mematuhi maka saya katakana mau di bantu lagi apa tidak (JN.1)

dari responden lainya mengatakan

.....kami setiap bulannyo dapat bantuanlah, minyak sayur, beras, token listrik.. makanya kita semua nurut samo bapak itu....(GN.1)

Kehadiran pendamping keagaaman ini memberikan suatu dorongan yang cukup besar, sehingga untuk 
melakukan pengerakan perialaku hidup bersih dan sehat, dilakukan oleh pendamping dan ini akan di lakukan misalnya untuk membersihkan rumah, mengepel lantai dan memnyapu halaman rumah. hal ini dapat di sampaikan oleh responden:

... saya selalu memberikan pesan dengan warga untuk selalu bersihkan rumah... mudah-mudahan mau mengikutinya.

pendapat responden lainya mengatakan bahwa :

...kami menurut saja apo yang di bilangmyo (pendamping) katonyo bersihkan rumah kia bersihkan.....(WG.3)

Dari hasil wawancara mendalam observasi dan telaah dokument di dapat kan bahwa kebersihan lingkungan warga SAD di pemukiaman desa Sialang, tidak menunjukkan kebersihan. misalnya lingkungan rumah yang terlihat sampah masih berserakan. hal ini di sebabkan tidak rutinya membersihkan di sekeliling lingkungan rumah sehingga banyak tumpukan-tumpukan sampah di sekitar rumah. Dari hasil observasi sebahagian besar kondisi peralatan dapur di pemukiman masih berserakan hal ini menunjukkan kurung perhatiannya ibu dalam membersihkan peralatan dapur, sisa-sisa makan bertumpuk di peralatan dapur warga. untuk itu Upaya-upaya untuk memberikan kesadaran dengan cara pendampingan dengan memberikan contoh lebih banyak serta media yang sesuai dengan kondisi sangat di butuhkan. Media dengan mendongeng kepada anak meruapakan media yang cocok karena sebahagian besar warga belum bisa membaca dan menulis. Dari hasil penelitian di dapatkan Perlunya pengembangan KIE, simulasi, dan dialog sebagai upaya promosi PHBS khususnya terkait kepercayaan kesehatan pada masyarakat Suku Taburta perlu melibatkan peran serta tokoh adat/kepala suku sebagai penutur asli nilai dan norma masyarakat Suku Taburta ${ }^{5}$. selain itu perlu dilakukan upaya pendampingan-pendampingan dalam meningkatkan perilaku sehat. pendampinag-pendampingan yang di lakukan dengan tinggal bersama warga SAD rombong ganta akan dapat mempercepat perubahan perilaku. Pemberdayaan KAT dalam meningkatkan kesejahteraan di pengaruhi oleh Penguatan Modal sosial masyarakat melalui kegiatan penyuluhan pendampingan dan pelibatan masyarakat dalam proses pemberdayan secara optimal ${ }^{6}$,berlawanan dengan pendapat Mahmud \&Kusnadi ( 2010) Data yang diperoleh menunjukkan bahwa masyarakat SAD sebelum dibina di tempat yang baru dan setelah dibina, kualitas kehidupan sosial mereka tidak banyak berubah. Walaupun ada pembangunan infrastruktur, kehidupan sosial ekonomi mereka tidak mengalami perubahan bahkan lebih buruk, yakni mereka kehilangan unsur-unsur pengetahuan dan kebudayaan dalam kehidupan mereka. Pengetahuan merupakan domain yang paling penting dalam membentuk tindakan seseorang (over behaviour). Dari pengalaman dan penelitian, terbukti bahwa perilaku yang didasarkan oleh pengetahuan akan bertahan lama daripada perilaku yang tidak didasarkan pengetahuan ${ }^{7}$.

Dari hasil Observasi di lapangan kebersihan diri dari warga SAD Rombong Ganta sangat memprihatinkan, misalnya perilaku mandi menggunakan sabun, misalnya mandi dengan menggosok badan dengan baik sehingga kulit akan kelihatan sehat dan bersih. Kondisi ini tidak bisa hanya di lakukan penyuluhan saja tetapi perlu dukungan Tokoh yang menjadi panutan dalam upaya penggerakan ke perilaku sehat atau pendampingan dan memberikan contoh setiap hari. Anak-anak dalam keseharinnya sangat mandiri, kegiatan sehari misalnya mandi dilakukan sendiri, makan dan kegiatan lainya. kurangnya perhatian orang tua membuat anak-anak tidak mendapatkan bimbingan, sebaiknya menjaga kebersihan, sehingga perilaku sehari-hari haruslah mendatkan contoh untuk agar ada role model bagi mereka untuk berperilaku sehat. Dari hasil observasi warga SAD banyak menderita penyakit kulit gatal-gatal di sekujur tangan dan kaki terlihat hitam bertumpuk dan bengkak-bengkak menunjukkkan penyakit kulit yang menahun. Kebiasaan memotong kuku anak dan orang dewasa masih perlu mendapatkan uapaya dalam melakukan perilaku tersebut. Kuku terlihat Hitam dengan kotoran hal ini tentunya kan dapat menimbulkan sarana penyebaran penyakit. selain itu perilaku cuci tangan pakai sabun belum menjadi pada saat ini kebiasan cuci tangan sebelum makan di kerjakan tetapi tidak menggunkan sabun. mereka kerjakan hanya sebatas membasahkan tangan sebelum makan atau ketika ada kotoran di tangan. sehinga hal ini mengakibatkan sebahagian besar mereka penyakit diare. Permasalahan PHBS pada orang rimba seperti masih tingginya orang rimba melahirkan dengan dukun, masih adanya bayi yang tidak ditimbang secara berkala dan tidak diberi ASI eksklusif, masih adanya orang rimba tidak menggunakan jamban 
ketika BAB \& BAK, tidak melakukan sikat gigi, tidak menggunakan air bersih, tidak membuang sampah pada tempatnya, tidak membersihkan perkarangan, merokok, masih adanya tidak memiliki $\mathrm{KIS}^{2}$. hasil penelitian lain menunjukkan pencegahan penyakit dapat dilakukan sedini Mungkin dengan instrumen yang sederhana dan dapat di pahami warga $\mathrm{SAD}^{8}$. Perlunya Terjadinya diare di Kampung Taria disebabkan oleh kurangnya kesadaran masyarakat dalam mengelolah air minum Sistem pemipaan air yang yang sering bermasalah disebabkan kurangnya pengawasan dan supervisi oleh pemerintah ${ }^{9}$. Jika dilihat dari pengertian PHBS merupakan sekumpulan perilaku yang dipraktikan atas dasar kesadaran sebagai hasil pembelajaran yang menjadikan seseorang, keluarga, atau masyarakat mampu menolong dirinya sendiri (mandiri) di bidang kesehatan dan berperan aktif dalam mewujudkan kesehatan masyaraka ${ }^{10}$. Tujuan promosi kesehatan yaitu peningkatan pengetahuan (knowledge), perubahan sikap (attitude), dan ketrampilan atau tingkah laku (practice) yang berhubungan dengan masalah kesehatan. Tujuan utama promosi kesehatan adalah untuk meningkatkan kesadaran, menigkatkan pengetahuan kesehatan, pemberdayaan diri dan mempengaruhi sikap, pengambilan keputusan dan perubahan perilaku ${ }^{11}$. pelayanan kesehatan warga SAD yang selalu berpindah-pindah maka perlu menggabungan upaya promotif, preventif dan kuratif dan pengobatan tradisional dengan mobil khusus, atau yang dinamakan SAD Care. Perilaku hygine perorangan tentunya harus mendapat perhatian dengan baik. Warga SAD Rombong ganta sebaiknya setelah mendapatkan Rumah perlu mendapat pelatihan pelatihan untuk meningkatkan Skil di bidang kesehatan untuk hidup sehat. tenaga kesehatan harus melakukan pendampingan setiap hari sehingga perilaku sederhan tersebut bisa menjadi kebutuhan. Tenaga Kesehatan tidak bisa hanya satu bulan sekali atau pembinaan yang insidentil tetapi pendampingan yang menetap bersama warga $\mathrm{SAD}^{12}$.

Bantuan Rumah yang di berikan untuk warga SAD sebaiknya setelah menempati rumah di berikan di lakukan pendampingan untuk mempraktek cara hidup sehat. dari hasil observasi dan wawancara mendalam selama ini mereka tidak di ajarkan bagaiman cara hidup sehat. mengatur rumah dengan baik selayaknya rumah yang menjadi tempat Tinggal. Kondisi ini tentunya akan mempengaruhi warga SAD untuk berinteraksi dengan warga Lokal. dari hasil observasi dan wwancara mendalam beberapa perilaku hidup bersih yang harus siapkan adalah, mengepel lantai, memuka jendela, menggosok baju, melipat baju, membersihkan WC, menyapu halaman, mandi dengan memakai sabun dan mengggosok dengan baik, menyetrika baju, memasak makanan, merebus air sebelum di minum. yang termasuk dalam faktor pemungkin yaitu ketersediaan sarana kesehatan, ketersediaan sarana transportasi akan berdampak pada respon masyarakat untuk berpartisipasi dalam program-program kesehatan. Semakin baik kondisi kebersihan rumahnya makan akan semakin mudah warga SAD ber interaksi dengan warga lokal. menjadi beberapa kendala adalah kuranya di fasilitas yang di berikan misalnya lemari pakaian ${ }^{13}$. hal ini sejalan dengan penelitian lain Institusi lokal diketahui bahwa peran pemerintah sejauh ini masih belum optimal karena pemerintah memfokuskan pada sosialisasi dan pengetahuan masyarakat komunitas adat terpencil terhadap program pemberdayaan, namun tidak diiringi dengan pembangunan sarana prasana serta fasilitas yang dibutuhkan masyarakat seperti pendidikan dan kesehatan ${ }^{14}$. Tingkat ekonomi mempengaruhi terhadap perilaku kesehatan. ${ }^{15}$. Beberapa masyarakat memiliki keyakinan penyulit pada saat menghadapi persalinan disebabkan oleh roh jahat dari penyihir Zambia yang hanya bisa ditangani oleh dukun bayi ${ }^{16}$ Pengetahuan masyarakat Suku anak dalam tentang malaria masih jauh dari yang diharapkan karena kurangnya informasi dari berbagai sumber, terutama dari tenaga kesehatan yang memang tidak ada dan wilayah yang jauh dan sulit dijangkau juga berpengaruh terhadap perkembangan informasi yang mereka terima Pembangunan bidang kesehatan tidak hanya sebatas pembinaan yang sifatnya insidentil tetapi perlu menyiapkan tenaga kesehatan masyarakat yang menetap dan memberikan contoh perilaku sehat setiap hari ${ }^{17}$.

Banyak rumah-rumah yang di berikan terkadang di tinggalkan oleh warga SAD hal ini di sebabkan kondisi lingkungan mereka yang sulit beradaptasi dengan pemukiman yang di bangun. perubahan mata pencaharian menjadikan mereka kesulitan dalam memenuhi kebutuhan hidupnya. pekerjaaan berburu sangat sulit, penghasilan lain 
belum bisa mereka kerjakan hal inilah menjadikan rumah-rumah di tinggalkan dan membuat ketidak berdayaan dalam memenuhi kebutuhan hidupnya.di warga Sialang yang menjadikan mereka tetap bertahan di pemukiman adalah adanya program oleh pemuka agama. pemuka agama ini memberikan bantuan berupa beras minyak sayur dan kebutuhan, kebutuhan lainya sehingga untk kehidupan bulan mereka masih bisa bertahan hidup dan tidak memikirkanknnya. Terhadap praktek marginalisasi yang telah terjadi tersebut negara harus bertanggung jawab dengan hadir untuk membela dan memberdayakan mereka ${ }^{18}$. Pemberdayaan masyarakat miskin, melalui Penguatan kapasitas kelembagaan menyusun rencana kerja dan membuka jaringan dan menghubungkanya dengan kelembagaan supra-desa, baik pemerintah, swasta dan NGO Nasioal dan Internasional ${ }^{19}$. Perlu adanya pemberdayaan dengan memanfaatkan kearifan lokal meningkatkan ekonomi dan di dukung oleh pemerintah ${ }^{20}$. terjadinya diare di Kampung Taria disebabkan oleh kurangnya kesadaran masyarakat dalam mengelolah air minum. Sistem pemipaan air yang yang sering bermasalah disebabkan kurangnya pengawasan dan supervisi oleh pemerintah ${ }^{10}$. Pemberdayaan yang dilakukan masih kurang menunjukkan tingkat keberhasilan seperti yang diharapkan ${ }^{21}$. Salah satu penyebabnya karena pola komunikasi yang masih perlu diperbaiki. Pola pemberdayaan selama ini menimbulkan dampak-dampak negatif terhadap suku anak dalam itu sendiri. nilai-nilai yang dianut masyarakat Indonesia tidak sesuai dengan budaya Suku Anak Dalam 2. Pengembangan proses pemberdayaan masyarakat bidang kesehatan disarankan untuk diarahkan Pengembangan proses pemberdayaan masyarakat bidang kesehatan disarankan untuk diarahkan pada proses pemberdayaan dan pemanfaatan sumber daya di dalam masyarakat serta proses fasilitasi dan dukungan dari luar masyarakat 22. Faktor penghambat perkembangan motorik adalah kurangnya perhatian pemerintah, penebangan liar, dan pembukaan lahan perkebunan ${ }^{23}$. Medis modern dengan cepat diterima masyarakat karena sosialisasi dan peran petugas kesehatan, pemerintah maupun fasilitas pelayanan kesehatan dari perusahaan-perusahaan yang beroperasi di wilayah
Sumuri. ${ }^{24}$ Pemberian bantuan sarana dan prasarana pendidikan kepada anak-anak SAD meningkatkan pemahaman anak-anak dalam belajar, mengaji dan praktek ibadah ${ }^{25}$. Salah satunya Suku Anak Dalam yang masih menganut budaya melangun yang menyebabkan terhambatnya aktifitas yang dilakukan Suku Anak Dalam terhenti lalu mereka mencari tempat hunian lain dihutan. oleh karena itu pola pendampingan yang harus di lakukan dengan membantu sampai pada kemampuan warga untuk lebas dari kehidupan berburu dengan cara memberikan ketrampilan misalnya berternak, menukang, dan berkebun agar warga SAD sialang dapat bertahan hidup di tengah kemajuan zaman. pendampingan itu dengan cara memberikan contoh dulu cara kita beternak, berkebun dan menanam sayuran ketika hasilnya Nampak maka mereka akan mengikuti apa yang menjadi harapan warga

\section{KESIMPULAN DAN SARAN}

1. Konsep perilaku hidup bersih dan sehat bagi warga suku anak dalam di rombong ganta desa sialang kecamatan pamenang yang harus disiapkan setelah pindah rumah dari pemukiman sudung ke pemukiman Menetap yang di bangun pemda adalah : mencuci tangan pakai sabun, mandi pakai sabun, menggosok gigi, mengepel lantai, melipat baju, membuka jendela setiap pagi, menggosok pakaian, memasak makanan yang bergizi. menyapu halaman, mencuci baju. menyisir rambut, memotong kuku. membuka jendela

2. Dalam melakukan perubahan perilaku hidup bersih dan sehat warga SAD Rombong ganta yang menetap di pemukinan dari kehidupan melangun (Sudung) maka harus di lakukan pendampingan dan tinggal bersama warga SAD tersebut lebih lama. Dengan demikian warga SAD dapat mencontoh perilaku-perilaku yang diajarkan dalam mempraktekkan perikau hidup bersih dan sehat setiap

\section{SARAN}

1. Pemerintah daerah menyiapkan petugas pendamping yang tinggal bersama warga yang mendapatkan bantuan pemukiman dengan kualifikasi atau berlatar belakang tenaga 
Kesehatan Masyarakat untuk bidang perilaku Hidup bersih dan sehat .

2. Melatih Warga SAD untuk meningkatkan Ketrampilan berwirausaha, atau bertani, berternak sehingga mengubah mata pencaharian dari berburu ke bidang lainya.

3. Memberikan Jatah Hidup sebelum mampu menyiapkan warga SAD mandiri

\section{DAFTAR PUSTAKA:}

1. Disdukcapil Provinsi Jambi. Data Warga Komunitas Adat Terpencil Suku Anak Dalam dan Suku Duano di Provinsi Jambi berdasarkan Hasil Verifikasi. 2014.

2. Saputra \& Ummi, upaya meningkatkan pengetahuan dan keterampilan perilaku hidup bersih dan sehat (phbs) orang rimba melalui pembinaan PHBS Rumah Tangga, Jurnal Pengabdian dan pemberdayaan Masyarakat, Volume 2 No. 2 September 2018

3. Takiddin. Nilai-nilai kearifan budaya lokal orang rimba (studi pada suku minoritas rimba di kecamatan air hitam provinsi jambi).2014. Sosio Didaktika. 1 (2). 161-169.

4. Mulyadi, M., 2013. Pemberdayaan Masyarakat Adat dalam Pembangunan Kehutanan. Jurnal Penelitian Sosial dan Ekonomi Kehutanan, Volume 10

5. Sargiem Kearifan Lokal Komunitas Adat Terpencil Suku Taburta dalam Perilaku Hidup Bersih dan Sehat, JURNAL MKMI, Desember 2015, hal. 218-227

6. Bahua, M.I.. Model Pengembangan Pemberdayaan Masyarakat Komunitas Adat Terpencil di Kabupaten Boalemo, Idea, 2015 - junal Pendidikan social dan budaya Volume 1. hal. 289-292.

7. Notoatmodjo, Soekidjo. Promosi kesehatan dan Perilaku Kesehatan. Jakarta : Rineka cipta. 2012.

8. Izhar, Uji coba Algoritma MTBS dalam kartu deteksi penyakit pada balita suku Anak dalam desa hajran kecamatan batin XXIV kabuapten Batanghari. 2019. Jurnal Kesas Jambi (JKMJ) V01.3 N0.1 september 2019

9. Kazmi SU, Khan RU. A Model to Study the Effect of Boiling on Water Borne Bacterial Diarrheal Agents. Can J App Sci. 2013;3(4):491-95
10. Depkes RI. Keputusan Menteri Kesehatan RI Nomor 1114/Menkes/SK/VII/2006 tentang Pedoman Pelakasanaan Promosi Kesehatan di Daerah. Jakarta : Depkes RI. 2006

11. Ewless, L.,\& Simnett, I. Promoting Health, A Practical Guide, Second Edition (1985) (Edisi Terjemahan), Hasanbasri, M.Emilia,O. 1994 (alih bahasa), Promosi Kesehatan Petunjuk Praktis, Edisi Kedua, Yogyakarta : Gadjah Mada University Press

12. Ridwan \&Oka Lesmana Model pemberdayaan suku anak dalam bidan Kesehatan di Kecamatan batin XXIV Kabupaten Batanghari, JKMJ Vol. 2, No. 2, September 2018

13. Green L and Kreuter W. Health Promotion Planning an Educational and Environmental Approach. ( Second Edition). Mayfield Publising Company. London. 2000

14. Sujarwani, et all Pemberdayaan masyarakat komunitas adat terpencil (KAT) oleh Pemerintah Lingga, Kepulauan Riau. Jurnal antropologi isu-isu sosial budaya. Juni 2018, vol. 20 (1): 17-31. (2018),

15. Hasan, Pemberdayaan Sosial Ekonomi Komunitas Adat terpencil (KAT) dalam rangka pengentasan Kemiskinan 2013; Jurnal Sosiologi USK.Juni 2013; Vol.3(3):77-91

16. Yenni , Studi sosial budaya masyarakat suku anak dalam tentang malaria dan cara pemberantasannya SPIRAKEL 2016, Vol 6, Desember 2014: 8-13

17. Kumbani, L., Bjune, G., Chirwa, E. \& Odland,J. Ø. Why Some Women Fail to Give Birth at Health Facilities: A Qualitative Study of Women's Perceptions of Perinatal Care From Rural Southern Malawi 2013. Reproductive health. 2013;10(9).

18. Muchlis, et all (, sejarah marginalisasi orang rimba bukit dua belas di era orde baru, paramita: historical studies journal, 26(2), 2016

19. Erwin, model pemberdayaan masyarakat mentawai melalui penguatan kelembagaan lokal di pulau siberut, 2015 sosio konsepsia vol. 04, no. 02, januari - april, tahun 2015

20. Suradi Kebijakan pemebrdayaan Komunitas adat terpencil; 2013.Jakarta p3KS Press

21. Nahri idris Mengkaji ulang pola komunikasi pemerintah dalam pemberdayaan suku anak dalam di provinsi jambi jurnal penelitian 
pers dan komunikasi pembangunan vol. 21 no.1 juni 2017: 37-48, 2017,

22. Sulaeman, et all. Model Pemberdayaan Masyarakat Bidang Kesehatan, Studi Program Desa Siaga Kesmas, Jurnal Kesehatan Masyarakat Nasional Vol. 7, No. 4, November 2012

23. Barlian \& Yusra Aktivitas Motorik Suku Anak Dalam Desa Muaro Kelis, Kecamatan Tengah Ilir, Kabupaten Tebo Provinsi Jambi, Prosiding Seminar Nasional Pascasarjana (SNP) Unsyiah 2017, April 13, 2017.

24. Tri ratnawati. Dominasi Medis Modern Atas Medis Tradisional Suku Sumuri, Teluk Bintuni, Papua Barat 2017. Masyarakat, Kebudayaan dan Politik Vol. 30, No. 2, tahun 2017, hal 174-187

25. Naswir et al, Peningkatan kualitas pendidikan untuk anak suku anak dalam di dusun selapik, Kabupaten Muaro Jambi .2018; jurnal karya abdi masyarakat volume 1 nomor 1 Januari - Juni 2018 